\title{
MEDIDAS PROTETIVAS DE URGÊNCIA E AÇÕES CRIMINAIS NA LEI MARIA DA PENHA: UM DIÁLOGO NECESSÁRIO
}

\author{
Artenira da Silva e Silva ${ }^{1}$ \\ Thiago Gomes Viana ${ }^{2}$
}

\begin{abstract}
Resumo:
O presente estudo adotou a pesquisa bibliográfica e jurisprudencial como metodologia básica para discorrer acerca da natureza jurídica das Medidas Protetivas de Urgência (MPUs) da Lei $\mathrm{n}^{\mathrm{o}}$ 11.340/2006 (Lei Maria da Penha), notadamente no que diz respeito à sua relação com ações criminais também pautadas nesse diploma legal. Objetivando evidenciar os aspectos positivos e negativos da conexão entre tais mecanismos, serão abordados, preliminarmente, o conceito e as peculiaridades caracterizadoras das MPUs. Subsequentemente, será investigada a natureza cível ou penal das MPUs, e analisada a relação destas com as supramencionadas ações criminais, observando também o entendimento jurisprudencial sobre o tema.
\end{abstract}

Palavras-chave: Lei Maria da Penha; Medidas Protetivas de Urgência; Ações criminais.

\section{PROTECTIVE MEASURES OF EMERGENCY AND CRIMINAL PROSECUTION IN THE MARIA DA PENHA LAW: A NECESSARY DIALOGUE}

\begin{abstract}
:
The present study adopted a bibliographical and jurisprudential research as the basic methodology to discuss the legal nature of the Emergency Protection Measures (EPMs) of the Law 11.340/2006 (Maria da Penha Law), especially regarding its relationship with criminal actions also under this legal diploma. Aiming to highlight the positive and negative aspects of the connection between these mechanisms, the concept and peculiarities of the EPMs will be approached preliminarily. Subsequently, the civil or criminal nature of the measures will be investigated, and their relationship to the mentioned criminal actions and the jurisprudential understanding of the present issue will be analyzed.
\end{abstract}

Keywords: Maria da Penha Law; Emergency Protective Measures; Criminal prosecution.

\footnotetext{
${ }^{1}$ Pós-doutora em Psicologia e Educação pela Universidade do Porto. Doutora em Saúde Coletiva pela Universidade Federal da Bahia. Mestre em Saúde e Ambiente pela Universidade Federal do Maranhão, Graduada em Psicologia pela Pontifícia Universidade Católica de São Paulo. Docente e pesquisadora do Departamento de Saúde Pública e do Mestrado em Direito e Instituições do Sistema de Justiça da Universidade Federal do Maranhão. Coordenadora de linha de pesquisa do Observatório Ibero Americano de Saúde e Cidadania e do Observatorium de Segurança Pública (PPGDIR/UFMA/CECGP). Psicóloga clínica e forense.

${ }^{2}$ Mestrando em Direito e Instituições do Sistema de Justiça pela Universidade Federal do Maranhão (UFMA). Pós-graduando em Direito Penal e Criminologia pelo Instituto de Criminologia e Política Criminal (ICPC)/Centro Universitário Internacional (UNINTER). Professor de Direito Penal da Unidade de Ensino Superior Dom Bosco (UNDB). Co-coordenador do Grupo de Estudos em Direito Constitucional (GEC), da OAB/MA. Advogado.
} 


\section{INTRODUÇÃO}

A Lei $n^{\circ} 11.340 / 2006$ nasceu como o mais importante marco legal de enfrentamento à violência de gênero no âmbito doméstico no Brasil. Cronologicamente, em 1994, o país sediou, na cidade de Belém do Pará, o evento da Organização dos Estados Americanos (OEA), que resultou na aprovação da "Convenção Interamericana para Prevenir, Punir e Erradicar a Violência contra a Mulher”. Em contrapartida, o tema da violência doméstica e/ou intrafamiliar contra a mulher apenas evoluiu da invisibilização do "estado de coisas" para um “problema político", quando o país foi responsabilizado pela Comissão Interamericana de Direitos Humanos (CIDH) no caso Maria da Penha. A própria Lei n ${ }^{\circ}$ 11.340/2006 (Lei Maria da Penha - LMP) nasceu no bojo das recomendações da CIDH ao Brasil.

Após uma década da aprovação da Lei Maria da Penha, com todos os avanços que já poderiam ter sido alcançados, identifica-se uma série de dificultadores e desafios a serem superados para que esse diploma legal seja, de fato, efetivado: escassez das delegacias tanto quanto das varas especializadas e, em especial, a hipossuficiência técnica dos operadores do direito, sobretudo quanto a terem conhecimentos específicos no que diz respeito à violência intrafamiliar e/ou doméstica e de gênero. Em suma, a violência institucional por imperícia perpetrada contra a vítima, ao buscar a proteção do Sistema de Justiça, precisa ser superada.

Diante disso, primeiramente, analisam-se o conceito $\mathrm{e}$ as peculiaridades caracterizadoras das MPUs, especialmente no tocante à sua natureza jurídica, o que implica sobremaneira a definição do juízo competente para seu julgamento, se de natureza cível ou criminal, e, por conseguinte, dos impactos da efetividade das medidas deferidas. Por conseguinte, verifica-se em que medida há uma conexão ou não entre as MPUs e as ações criminais decorrentes da LMP, finalizando com a descrição de como se dá o tratamento dessa possível relação pelo Poder Judiciário.

\section{MEDIDAS PROTETIVAS DE URGÊNCIA: conceito e suas peculiaridades} caracterizadoras

\footnotetext{
3 Entende-se por "estado de coisas" a "situação que se arrasta durante um tempo razoavelmente longo, incomodando grupos de pessoas e gerando insatisfações sem, entretanto, chegar a mobilizar as autoridades governamentais. Trata-se de uma situação que incomoda, prejudica, gera insatisfação para muitos indivíduos, mas não chega a constituir um item da agenda governamental, [...] não se encontra entre as prioridades dos tomadores de decisão". (RUA, 2012, p. 68).
} 
Seria o Direito Penal um instrumento importante no combate à violência doméstica? Sobre a tensão entre o Direito e as mulheres, Silvia Pimentel e Valéria Pandjiarjian (1996) salientam:

\begin{abstract}
A questão da busca ou não da ajuda da lei parece-nos demonstrar a ambiguidade já apontada com que o Direito se apresenta a essas mulheres, ou talvez, melhor dizendo, como elas o percebem. Por um lado, é visível a valorização do Direito enquanto proteção ou expectativa de proteção; mas, por outro, percebemos que as mulheres jamais perdem a dimensão da realidade fática que corrobora a idéia (sic) do distanciamento que existe entre a lei e a vida, em última instância, entre Estado e Sociedade. (PIMENTEL; PANDJIARJIAN, 1996, p. 37).
\end{abstract}

Considerando que um ponto nevrálgico da LMP consiste em estabelecer a "[...] integralidade no tratamento da violência doméstica [...] [quando prevê] aliança entre as medidas assistenciais, as de prevenção e as de contenção da violência, além do vínculo da esfera jurídica com os serviços de assistência em rede" (CAMPOS; CARVALHO, 2011, p. 144), as MPUs consubstanciam um importante mecanismo que altera a própria lógica punitiva, já que se preocupa, de imediato, com a preservação da segurança e vida da vítima.

Nesse sentido, se de um lado tem-se o eixo punitivo (arts. 17, 20 e 41 a 45) e as críticas da criminologia crítica à seletividade e ineficiência do Direito Penal, bem como da própria estigmatização do agressor ${ }^{4}$, de outro é inegável o caráter positivo do eixo protetivo/preventivo (arts. $9^{\circ}-12,18-21,23,29$ ) da LMP, na qual as MPUs estão inseridas. A previsão das MPUs na LMP, segundo Rosane M. Reis Lavigne e Cecília Perlingeiro (2011, p. 292), está em sintonia com o standard registrado no Protocolo de Actuación para Operadores de Justicia frente a la Violência contra las Mujeres en el Marco de las Relaciones de Pareja. ${ }^{5}$

Assim, as "medidas não penais de proteção à mulher em situação de violência [...] mostram-se providências muito mais sensatas para fazer cessar as agressões e, ao mesmo

\footnotetext{
4 "Apesar das críticas direcionadas à Lei Maria da Penha no sentido de tratar-se de lei eminentemente punitiva, destaca-se que a prisão preventiva nos casos desta lei possui natureza ainda mais excepcional do que em outras hipóteses legais. Afinal, as medidas protetivas emergem como uma novidade extremamente positiva da lei e representam alternativa real ao encarceramento". (LAVIGNE; PERLINGEIRO, 2011, p. 300).

5 "A obrigação de proteger com a devida diligência exige que os Estados garantam às mulheres [...] que são vítimas de violência ou correm risco de sê-lo tenham acesso à justiça e a serviços de atenção à saúde e apoio que respondam às suas necessidades imediatas, as protejam contra outros danos e se ocupem das consequências que se derivam da violência para a mulher. Com esse fim, os Estados devem elaborar marcos legislativos, sistemas de vigilância policial e procedimentos judiciais apropriados para proteger adequadamente a todas as mulheres, proporcionar-lhes um ambiente seguro e propício para que informem os atos de violência cometidos contra elas e adotar medidas tais como ordens de interdição ou expulsão e procedimento de proteção às vítimas. Em situações nas quais é evidente que determinadas mulheres e meninas podem ser vítimas de violência, os órgãos encarregados de aplicar a lei também têm a obrigação de estabelecer mecanismos de proteção efetivos e apropriados para impedir que se produzam outros danos" (NASH, 2011, p. 9, tradução nossa).
} 
tempo, menos estigmatizantes para o agressor". (CELMER; AZEVEDO, 2007, p. 15-17). A

respeito desse aspecto, Rosane M. Reis Lavigne e Cecília Perlingeiro (2011) lecionam:

\begin{abstract}
Dados do Conselho Nacional de Justiça - CNJ mostram que as medidas protetivas de urgência constituem o procedimento mais aplicado pelos Juizados especializados, representando cerca de $60 \%$ da atuação dos mesmos. Desde 2006, ano de início de vigência da lei, até o ano de 2010 foram deferidas 96.098 medidas protetivas contra 11.659 prisões deferidas, ou seja, existe uma relação média de 1 prisão para cada 8 medidas protetivas deferidas. A prática tem confirmado que as medidas protetivas são uma mostra evidente de que o tratamento prioritário que se pretende dar aos direitos humanos das mulheres na pauta estatal não está em desalinho com o esforço de contenção do poder punitivo. A utilização criteriosa e adequada das medidas protetivas pode conferir às mulheres a proteção necessária e o desencarceramento desejado pelas orientações garantistas. Desta forma, a despenalização e a descriminalização de condutas devem ser o parâmetro norteador da política criminal. (LAVIGNE; PERLINGEIRO, 2011, p. 293).
\end{abstract}

Conforme dispõe a LMP, há duas espécies de MPUs: as que obrigam o ofensor, previstas no art. $22^{6}$ do diploma legal, e aquelas que salvaguardam a vítima, previsto nos arts. 23 e $24^{7}$.

\footnotetext{
6 “Art. 22. Constatada a prática de violência doméstica e familiar contra a mulher, nos termos desta Lei, o juiz poderá aplicar, de imediato, ao agressor, em conjunto ou separadamente, as seguintes medidas protetivas de urgência, entre outras: I - suspensão da posse ou restrição do porte de armas, com comunicação ao órgão competente, nos termos da Lei no 10.826, de 22 de dezembro de 2003; II - afastamento do lar, domicílio ou local de convivência com a ofendida; III - proibição de determinadas condutas, entre as quais: a) aproximação da ofendida, de seus familiares e das testemunhas, fixando o limite mínimo de distância entre estes e o agressor; b) contato com a ofendida, seus familiares e testemunhas por qualquer meio de comunicação; c) freqüentação de determinados lugares a fim de preservar a integridade física e psicológica da ofendida; IV - restrição ou suspensão de visitas aos dependentes menores, ouvida a equipe de atendimento multidisciplinar ou serviço similar; V - prestação de alimentos provisionais ou provisórios. $\S 1^{\circ}$ As medidas referidas neste artigo não impedem a aplicação de outras previstas na legislação em vigor, sempre que a segurança da ofendida ou as circunstâncias o exigirem, devendo a providência ser comunicada ao Ministério Público. § $2^{\circ} \mathrm{Na}$ hipótese de aplicação do inciso I, encontrando-se o agressor nas condições mencionadas no caput e incisos do art. $6^{\circ}$ da Lei no 10.826, de 22 de dezembro de 2003, o juiz comunicará ao respectivo órgão, corporação ou instituição as medidas protetivas de urgência concedidas e determinará a restrição do porte de armas, ficando o superior imediato do agressor responsável pelo cumprimento da determinação judicial, sob pena de incorrer nos crimes de prevaricação ou de desobediência, conforme o caso. $\S 3^{\circ}$ Para garantir a efetividade das medidas protetivas de urgência, poderá o juiz requisitar, a qualquer momento, auxílio da força policial. $\S 4^{\circ}$ Aplica-se às hipóteses previstas neste artigo, no que couber, o disposto no caput e nos $\S \S 5^{\circ}$ e $6^{\circ}$ do art. 461 da Lei no 5.869, de 11 de janeiro de 1973 (Código de Processo Civil).” (BRASIL, 2006).

7 “Art. 23. Poderá o juiz, quando necessário, sem prejuízo de outras medidas: I - encaminhar a ofendida e seus dependentes a programa oficial ou comunitário de proteção ou de atendimento; II - determinar a recondução da ofendida e a de seus dependentes ao respectivo domicílio, após afastamento do agressor; III - determinar o afastamento da ofendida do lar, sem prejuízo dos direitos relativos a bens, guarda dos filhos e alimentos; IV determinar a separação de corpos.

Art. 24. Para a proteção patrimonial dos bens da sociedade conjugal ou daqueles de propriedade particular da mulher, o juiz poderá determinar, liminarmente, as seguintes medidas, entre outras: I - restituição de bens indevidamente subtraídos pelo agressor à ofendida; II - proibição temporária para a celebração de atos e contratos de compra, venda e locação de propriedade em comum, salvo expressa autorização judicial; III suspensão das procurações conferidas pela ofendida ao agressor; IV - prestação de caução provisória, mediante depósito judicial, por perdas e danos materiais decorrentes da prática de violência doméstica e familiar contra a ofendida. Parágrafo único. Deverá o juiz oficiar ao cartório competente para os fins previstos nos incisos II e III deste artigo". (BRASIL, 2006).
} 
Conforme estabelece o art. 18 da LMP, os requerimentos de MPUs são encaminhados ao magistrado, cuja decisão sobre tal pedido a ser tomada, independentemente de audiência das partes ou de manifestação do representante do Ministério Público, deve se efetivar no prazo máximo de 48 horas. Além disso, é incumbido ao magistrado determinar o encaminhamento da vítima, caso considere necessário, ao órgão de assistência judiciária, bem como cientificar o Ministério Público quanto ao deferimento das MPUs e crimes denunciados. De fundamental importância seria também o encaminhamento do agressor para atendimento especializado ou de reeducação quando do deferimento de tais medidas, especialmente porque, diante do fato, pode haver uma naturalização introjetada no que diz respeito à violência contra a mulher. Frequentemente, o agressor não considera ou sequer percebe que cometeu um ato de violência, devendo o próprio encaminhamento constituir uma medida protetiva de urgência.

Em que pese o exposto, há o obstáculo do próprio desconhecimento das mulheres quanto às hipóteses de cabimento ou não das MPUs e, ainda, o descrédito quanto à sua efetividade. Um interessante trabalho realizado na cidade de Porto Alegre/RS traz o depoimento de um operador do Direito do MP, que, sem tocar nos obstáculos para a aplicação da lei, ou mesmo nas fragilidades do sistema policial na proteção às mulheres, asseverou:

\footnotetext{
A medida de afastamento contra o agressor é uma medida extremamente severa na vida dos dois, porque tem consequências tanto para a pessoa que vai ficar em casa, como para a pessoa que vai sair. Depois que a polícia vai embora, ele mete o pé na porta e arrebenta ou mata ela, e a mulher fica desprotegida, ela não vai ficar com um policial na porta, então a medida é perigosa também. A gente não tem como saber o que vai acontecer, todo mundo pede medida de afastamento, já tá na boca do povo. Âs vezes a violência que elas se referem é a do casamento desgastado e daí a solução desse casal não é aqui, simplesmente retirar uma pessoa de casa. (MENEGHEL et al., 2011, p. 747).
}

Ainda sobre essa pesquisa, uma das mulheres em situação de violência relatou seu descrédito quanto à efetividade das MPUs, já que nada aconteceria quando de seu descumprimento por parte dos agressores:

Qualquer coisa que acontecesse era para chamar a polícia e mostrar a medida protetiva, mas até a polícia chegar deu né, já tá feito o dano [...] Agora tu chama ligeiro e eles dizem que não têm viatura, diz que não podem entrar dentro de casa, certo? Aí o cara quebra a cara da gente e a gente tem que ficar quieta. (Mulher em situação de violência). (MENEGHEL et al., 2011, p. 747).

Pesquisa semelhante, realizada na cidade de Belo Horizonte/MG, traz o seguinte diagnóstico: 
Os problemas em torno das medidas protetivas são diversos. Apenas para referir a dois que foram observados durante a pesquisa em Belo Horizonte pode-se mencionar o conteúdo do relato circunstanciado, que muitas vezes não fornece ao juiz elementos suficientes para decidir sobre a necessidade das medidas e nem mesmo sobre sua adequação. $\mathrm{O}$ caso de $\mathrm{M}$. tem elementos que ilustram essa dificuldade. A medida protetiva que lhe foi concedida pela justiça determinava que F., seu agressor, mantivesse uma distância de 200 metros da vítima. O que o Judiciário e a polícia pareciam desconhecer é que os dois eram vizinhos e a borracharia onde F. trabalhava estava situada a menos de 50 metros do salão de $\mathrm{M}$. Informações como essas parecem elementares demais, mas devem ser entendidas como essenciais pela polícia e pela Justiça, evitando que sejam deferidas medidas que não são adequadas à realidade vivida por aquela mulher. (PASINATO, 2010, p. 227).

No tocante à hipótese de as MPUs serem deferidas de ofício, concorda-se com Rosane

M. Reis Lavigne e Cecília Perlingeiro (2011), que destacam:

\begin{abstract}
Ao observar a sequência das providências que competem ao juiz após o recebimento do expediente da medida protetiva, Carvalho (2009: 92) anota como estranho o caminho escolhido pelo legislador. Chama-lhe atenção o juiz decidir primeiro e somente depois a ofendida ser encaminhada à assistência jurídica. Ainda observa que o Ministério Público toma conhecimento à posteriori da decisão judicial, momento em que lhe caberia examinar o caso e adotar as providências pertinentes. Tal encadeamento, segundo o citado autor, fugiria à regra comum processual, na qual a manifestação do Juízo tem por pressuposto a oitiva anterior das partes. Alega que a inversão assinalada arranharia ao princípio da imparcialidade. Entretanto, diante da urgência da medida pleiteada, ancorada em Lei fruto de ação afirmativa dos direitos da mulher, a excepcionalidade à regra processual comum se justifica pelos princípios da devida diligência do Estado e da ampla proteção da mulher. (LAVIGNE; PERLINGEIRO, 2011, p. 297, grifo nosso).
\end{abstract}

Não obstante as críticas quanto a uma suposta violação da autonomia da mulher para a qual fora concedida MPU de ofício, entende-se que o "poder geral de cautela aliado à proteção da integridade pessoal da mulher autoriza o magistrado a proceder dessa forma", já que, por ser leiga ou por outro motivo, a mulher não vislumbra as opções que melhor resguardam sua integridade moral e física (LAVIGNE; PERLINGEIRO, 2011, p. 299).

Ademais, em caso de descumprimento da MPU, além da decretação de prisão preventiva $^{8}$, Fredie Didier Jr. e Rafael Oliveira (2010) sustentam que, com base no art. 461,

\footnotetext{
8 “Art. 313. Em qualquer das circunstâncias, previstas no artigo anterior, será admitida a decretação da prisão preventiva nos crimes dolosos: [...] IV. Se o crime envolver violência doméstica e familiar contra a mulher, nos termos da lei específica, para garantir a execução das medidas protetivas de urgência". (BRASIL, 1941). Como toda espécie de prisão preventiva, se exige, igualmente, requisitos autorizadores de tão grave medida, quais sejam, o fumus comissi delicti e o periculum in libertatis.
} 
CPC/73, com o equivalente no art. 497 e ss. do CPC/15, é possível a imposição de multa como medida coercitiva:

\begin{abstract}
Sem dúvida alguma, o meio coercitivo indireto mais difundido - e, quiçá, um dos mais eficientes - é a multa coercitiva. Trata-se de medida de natureza processual que tem por objetivo compelir o devedor ao cumprimento da ordem judicial (caráter coercitivo). Justamente por isso, não pode ser irrisória, devendo ser fixada num valor tal que possa gerar no íntimo do agressor o temor do descumprimento. Também por ser coercitiva, a priori ela não tem teto, não tem limite, não tem valor pré-limitado. Se fosse punitiva, teria, como ocorre com a cláusula penal (art. 412 do Código Civil). Apesar de ser muito comum a utilização da multa diária, deve-se ver que a periodicidade de sua incidência nem sempre será essa. Pode ser, mas a multa também pode ser horária, semanal, mensal, anual ou até mesmo fixa. O caso concreto é que vai dizer. Assim, por exemplo, é possível ao magistrado determinar ao agressor que não se aproxime da residência ou do local de trabalho da ofendida, ou que não mantenha contato com ela, sob pena de multa fixa, incidente sempre que houver descumprimento da ordem. Em caso de desobediência, o montante acumulado reverterá em favor da ofendida. (DIDIER JR.; OLIVEIRA, 2010).
\end{abstract}

Sendo descumprida a MPU, há, ainda, a possibilidade de o agressor ser responsabilizado penalmente pelo crime de desobediência (art. 359, CP), conforme entendimento do egrégio STJ (Habeas Corpus no 220.392/RJ) e de parte da doutrina. Contudo, o STF, acertadamente, já assentou entendimento diverso em outra oportunidade:

\footnotetext{
Crime de desobediência e penalidade civil ou administrativa não se configura, sequer em tese, o delito de desobediência quando a lei comina para o ato penalidade civil ou administrativa. (STF, RT 613/413). A jurisprudência desta Corte firmou-se no sentido de que não há crime de desobediência quando a inexecução da ordem emanada de servidor público estiver sujeita à punição administrativa, sem ressalva de sanção penal. Hipótese em que o paciente, abordado por agente de trânsito, se recusou a exibir documentos pessoais e do veículo, conduta prevista no Código de Trânsito Brasileiro como infração gravíssima, punível com multa e apreensão do veículo (CTB, artigo 238). Ordem concedida. (BRASIL, 2006).
}

A LMP, a exemplo de tantas outras leis no país, ainda enfrenta sérios problemas de efetividade, os quais, boa parte, seriam solucionados caso fossem intensificadas não só as campanhas de conscientização sobre o fenômeno da violência doméstica e familiar contra a mulher, mas também a necessária e permanente formação dos operadores de Direito em questões de violência doméstica e de gênero. Essa última foi, inclusive, uma orientação da $\mathrm{CIDH}$, de modo a melhorar a aplicabilidade da LMP, especialmente no tocante às MPUs.

Superada essa análise inicial, discorre-se a seguir acerca da natureza jurídica híbrida das MPUs. 


\subsection{Natureza jurídica}

A natureza jurídica das MPUs é um dos pontos mais controversos na doutrina e jurisprudência quando o tema é violência doméstica e familiar contra a mulher. Há, basicamente, duas correntes, as quais são apresentadas a seguir.

A primeira corrente, majoritária, sustenta que as medidas protetivas previstas no art. 22, I, II e III da Lei consubstanciam medidas cautelares processuais penais (NUCCI, 2010, p. 1275-1280; SOUZA, 2009, p. 109-145; CUNHA; PINTO, 2008, p. 136; NILO BATISTA, 2009, p. 17; CAVALCANTI, 2007, p. 191), sendo as mesmas "aplicáveis unicamente para assegurar os meios e fins do processo em que se busca ou se irá buscar a realização da pretensão punitiva" (KARAM, 2006, p. 6-7). As MPUs constantes no art. 22, incs. IV e V, por sua natureza cível, conforme teor dos arts. 536 a 538 do CPC/15 (no CPC/73, arts. 806 a 808), demandariam o ajuizamento da ação principal no prazo decadencial de 30 dias, sob risco de extinção das MPUs deferidas liminarmente.

A segunda e minoritária corrente, por sua vez, da qual fazem parte Maria Berenice Dias (2012, p. 145 e ss.), Wilson Lavorenti (2009, p. 264) e Alice Bianchini (2011, p. 234), sustenta que as MPUs são um tipo de ação cível de caráter satisfativo, sem prazo de eficácia enquanto medida provisional $^{9}$ que são, de modo que dispensariam intentar a ação principal no prazo já referido. As duas únicas exceções seriam a proibição temporária de prática de negócios jurídicos (art. 24, inc. II, da LMP) e a de alimentos provisórios ou provisionais (CÂMARA, 2009, p. 260; CUNHA; PINTO, 2008, p. 144), que dependem necessariamente que a ação principal seja proposta no prazo de 30 dias. A duração ou revogação ficaria a cargo do magistrado, que decide a respeito. Sobre isso, Fredie Didier Jr. e Rafael Oliveira (2010) afirmam:

A Lei Maria da Penha prevê a possibilidade de concessão, em favor da mulher que
se alegue vítima de violência doméstica ou familiar, de medidas provisionais,
dando-lhes, porém, o nome de medidas protetivas de urgência. A natureza jurídica,
no entanto, como já anunciado, é a mesma: providências de conteúdo satisfativo,
concedidas em procedimento simplificado, relacionadas à parte do conflito (no caso,

\footnotetext{
9 “As medidas provisionais podem ser obtidas pela instauração de um procedimento cautelar embora sem conteúdo cautelar (ou seja, de caráter satisfativo). A demanda para a obtenção de tais medidas é satisfativa, mas se processa pelo procedimento cautelar, que é mais simples. As medidas provisionais ainda caracterizam-se por relacionar-se a uma parcela da lide: o demandante dirige-se ao Judiciário e pede uma providência que diz respeito a apenas parte do seu problema”. (DIDIER JR.; OLIVEIRA, 2010).
} 
do conflito familiar e doméstico). Em razão disso, muitas das características do antigo modelo de tutela provisional foram repetidas: a) possibilidade de obtenção de medida liminar (art. 19, § 1º , Lei Federal n. 11.340/2006); b) fungibilidade (art. 19, $\S 2^{\circ}$, Lei Federal n. 11.340/2006); c) a ação para a obtenção da "medida protetiva de urgência", por ser satisfativa, é apta à produção da coisa julgada material e dispensa o ajuizamento da ação principal em trinta dias. (DIDIER JR.; OLIVEIRA, 2010).

As MPUs exigem o "preenchimento de dois pressupostos: o fumus boni iuris (aparência do bom direito, traduzida em um começo de prova) e periculum in mora (perigo na demora, entendida como uma situação de urgência incontornável)". (CARVALHO, 2015, p. 63).

Entende-se, a despeito da respeitável posição majoritária, que as MPUs, essencialmente, possuem caráter civil. O entendimento em torno da medida, por ser de natureza penal, leva a algumas dificuldades práticas. Explica-se: uma mãe ajuizou uma MPU contra um de seus filhos que havia passado a agredi-la verbal e psicologicamente, além de ter proferido ameaças de morte em virtude de disputa de bens; daí, no primeiro grau, o juiz considerou que as MPUs têm natureza processual penal e são vinculadas a um processo criminal, tendo extinguido a ação das MPUs por ausência deste, contudo, a sentença foi reformada pelo Tribunal de Justiça de Goiás, com base no entendimento de que as MPUs gozam de caráter cível, o que fez com que o filho recorresse ao STJ dessa sentença. Na oportunidade, a $4^{\mathrm{a}}$ Turma do STJ decidiu pela aplicação da LMP em ação civil, sem existência de inquérito policial ou processo penal contra o suposto agressor, tendo o relator ministro Luís Felipe Salomão sustentado:

\begin{abstract}
Parece claro que o intento de prevenção da violência doméstica contra a mulher pode ser perseguido com medidas judiciais de natureza não criminal, mesmo porque a resposta penal estatal só é desencadeada depois que, concretamente, o ilícito penal é cometido, muitas vezes com consequências irreversíveis, como no caso de homicídio ou de lesões corporais graves ou gravíssimas. [...] franquear a via das ações de natureza cível, com aplicação de medidas protetivas da Lei Maria da Penha, pode evitar um mal maior, sem necessidade de posterior intervenção penal nas relações intrafamiliares. (BRASIL, 2014) ${ }^{10}$.
\end{abstract}

10 "DIREITO PROCESSUAL CIVIL. VIOLÊNCIA DOMÉSTICA CONTRA A MULHER. MEDIDAS PROTETIVAS DA LEI N.11.340/2006 (LEI MARIA DA PENHA). INCIDÊNCIA NO ÂMBITO CÍVEL. NATUREZA JURÍDICA. DESNECESSIDADE DE INQUÉRITO POLICIAL, PROCESSO PENAL OU CIVIL EM CURSO. 1. As medidas protetivas previstas na Lei n. 11.340/2006, observados os requisitos específicos para a concessão de cada uma, podem ser pleiteadas de forma autônoma para fins de cessação ou de acautelamento de violência doméstica contra a mulher, independentemente da existência, presente ou potencial, de processo-crime ou ação principal contra o suposto agressor. 2. Nessa hipótese, as medidas de urgência pleiteadas terão natureza de cautelar cível satisfativa, não se exigindo instrumentalidade a outro processo cível ou criminal, haja vista que não se busca necessariamente garantir a eficácia prática da tutela principal. "O fim das medidas protetivas é proteger direitos fundamentais, evitando a continuidade da violência e das situações que a favorecem. Não são, necessariamente, preparatórias de qualquer ação judicial. Não visam processos, mas pessoas" (DIAS. Maria Berenice. A Lei Maria da Penha na justiça. 3 ed. São Paulo: Editora Revista dos Tribunais, 2012). 3. "Recurso 
Com acerto, Júlia Maria Seixas Bechara (2012), defensora pública, sustenta:

\begin{abstract}
Para alguns, é possível que se entenda que o principal é o processo criminal. Todavia, essa vinculação traria inconvenientes, em especial a desproteção da mulher em caso de retratação da representação ou a manutenção dessa para garantia de vigência da ordem. Ademais, não se pode admitir que medida de natureza cível vincule-se a processo principal de caráter criminal. [...] Tal consequência, por demais gravosa, vai de encontro à razão de existência das próprias medidas protetivas. Se, de um lado, se constatam dificuldades para o ajuizamento das demandas, como o acesso à célere assistência jurídica, a obtenção de documentos necessários à propositura da ação ou mesmo a instabilidade emocional, de outro lado é possível que sequer exista a necessidade de outro feito, como mencionado anteriormente. De tal modo, a exigência de futura propositura de ação significaria nova desproteção à vítima, em atendimento a formalismo incompatível com o mecanismo de solicitação da ordem. (BECHARA, 2012, grifo da autora).
\end{abstract}

A definição da natureza jurídica das MPUs se reveste de grande importância, porque implica diretamente na definição da competência cível ou criminal de quem irá julgá-las. A indefinição hoje imperante quanto ao tema nos tribunais brasileiros é motivo de preocupação, especialmente por trazer grave insegurança jurídica não só para o agressor, mas também para a vítima. Eis o tema que se passa a tratar no tópico seguinte.

\title{
3. MPUs E AS AÇÕES PENAIS DA LMP: um diálogo necessário
}

Uma vez tomada a posição de que as MPUs são de natureza eminentemente cível, é mister explorar as consequências desse entendimento no tocante à competência e, por conseguinte, a relação dessas medidas com as ações penais calcadas na LMP ou não, desde que envolvendo o mesmo agressor e vítima.

Dispõe a LMP que Juizados de Violência Doméstica e Familiar contra a Mulher terão competência cível e criminal para o processo, o julgamento e a execução das causas decorrentes da prática de violência doméstica e familiar contra a mulher (art. 14) (BRASIL, 2006). Essa competência cumulativa, conforme entende Alexandre Câmara (2009, p. 258), tem por fundamento o princípio da unidade de convicção ${ }^{11}$.

especial não provido". (REsp. nº 1.419.421 - GO (2013/0355585-8), Min. Rel. LUIS FELIPE SALOMÃO. Julg.: $11 / 02 / 2014)$.

11 “[...] Ressaltando ser, em tese, da competência da justiça comum estadual o julgamento de ação de indenização baseada na legislação acidentária, entendeu-se que, havendo um fato histórico que gerasse, ao mesmo tempo, duas pretensões - uma de direito comum e outra de direito acidentário -, a atribuição à justiça do trabalho da competência para julgar a ação de indenização fundada no direito comum, oriunda do mesmo fato histórico, poderia resultar em decisões contraditórias, já que uma justiça poderia considerar que o fato está provado e a outra negar a própria existência do fato. Salientou-se que deveria intervir no fator de discriminação e de 
Como bem atenta Castilho (2011), apesar da LMP estabelecer que as causas cíveis decorrentes de violência doméstica e familiar contra a mulher devem ser tratadas pelo Juizado de Violência Doméstica e Familiar contra a Mulher, tendo em vista sua competência de natureza mista (penal e civil),

[...] a maioria dos (sic) Juizados declina da competência para a Vara de Família, onde o contexto de violência doméstica contra a mulher sequer é mencionado, olvidando inclusive medidas protetivas de urgência concedidas. Nos casos de guarda a violência vivenciada pela mulher e pelos filhos perde relevo em favor da manutenção da convivência familiar. Lembrar do contexto de violência é uma tarefa a ser assumida com mais vigor pelo Ministério Público, para que as decisões judiciais não reforcem a vitimização das mulheres. (CASTILHO, 2011).

Nesse sentido, o próprio Fórum Nacional de Juízes de Violência Doméstica e Familiar contra a Mulher (Fonavid) em seu enunciado 03 entende que a "competência cível dos Juizados de Violência Doméstica e Familiar contra a Mulher é restrita às medidas protetivas de urgência previstas na Lei Maria da Penha, devendo as ações relativas a direito de família ser processadas e julgadas pelas Varas de Família”.

Na jurisprudência, o tema também é objeto de controvérsia, como se pode ver dos julgados a seguir:

APELAÇÃO CRIMINAL - NATUREZA CÍVEL DAS MEDIDAS PROTETIVAS DE URGÊNCIA DA LEI 11.340/06 - APLICAÇÃO DO PROCEDIMENTO RECURSAL DO CPC - DECISÃO INTERLOCUTÓRIA, ATACÁVEL POR AGRAVO DE INSTRUMENTO - AUSÊNCIA DE REGULARIDADE FORMAL DO RECURSO - DESRESPEITO A NORMA PROCESSUAL CIVIL - PEÇA DE INTERPOSIÇÃO DE RECURSO DESACOMPANHADA DE RAZÕES - NÃO CONHECIMENTO. - [...] - Em que pese a competência das Câmaras Criminais para o julgamento de recursos que tratam de procedimentos relativos a medidas protetivas referentes à Lei 11.340/06 (matéria eminentemente cível), é o rito recursal previsto no Código de Processo Civil que deve ser aplicado a tais casos. V.V. - As decisões que deferem ou indeferem medidas protetivas não são definitivas ou com força de definitivas, mas interlocutórias, as quais são atacáveis por agravo de instrumento, conforme preveem os artigos 13 da Lei 11.340/06 c/c o artigo $162 \S 2^{\circ}$ e 522 e ss. do Código de Processo Civil. Não havendo na Lei 11.340/06 regra específica acerca do recurso cabível contra as decisões que deferem ou indeferem as medidas cautelares requeridas, o recurso de apelação interposto pelo Ministério Público deve ser conhecido, em atenção ao princípio da fungibilidade. (MINAS GERAIS, 2013).

interpretação dessas competências o que se chamou de 'unidade de convicção', segundo a qual o mesmo fato, quando tiver de ser analisado mais de uma vez, deve sê-lo pela mesma justiça. Vencidos os Ministros Carlos Britto, relator, e Marco Aurélio, que negavam provimento ao recurso, e declaravam a competência da justiça do trabalho". (RE 438639/MG, rel. orig. Min. Carlos Britto, rel. p/ acórdão Min. Cezar Peluso, 9.3.2005. (RE438639). 
LEI MARIA DA PENHA. MEDIDAS PROTETIVAS DEFERIDAS. AÇÃO PRINCIPAL NÃO PROPOSTA. EXTINÇÃO DO PROCESSO CAUTELAR SEM JULGAMENTO DO MÉRITO. POSSIBILIDADE. 1 - Não há, sobretudo no âmbito do direito penal, como manter indefinidamente uma medida cautelar que imponha restrições à liberdade de locomoção do indivíduo, sob pena de perpetuar um constrangimento ilegal, sem justa causa. 2 - Tendo as medidas protetivas caráter eminentemente cautelar, não ajuizada ação principal, seja ela cível ou criminal, extingue-se o processo sem o julgamento do mérito, em face da ausência de pressuposto de desenvolvimento válido e regular, revogando-se, por conseguinte, todas as restrições impostas ao suposto ofensor. 3 - Recurso não provido (TJMG, Proc. $n^{\circ}$ 1.0324.09.076211-7/001(1). Relator: Des. Antônio Armando dos Anjos. Data do julgamento: 20.07.2010. Data da publicação: 27.08.2010).

PROCESSUAL - CONFLITO NEGATIVO DE COMPETÊNCIA - RECURSO INTERPOSTO CONTRA DECISÃO PROFERIDA POR JUIZ CRIMINAL COM FUNDAMENTO NA LEI MARIA DA PENHA - COMPETÊNCIA DA TURMA CRIMINAL.1. O julgamento de recurso interposto contra decisão proferida em processo de medida cautelar submetida à jurisdição de Juizado Especial Criminal e de Violência Doméstica Familiar contra a Mulher, consubstanciada em medidas protetivas, é da competência de Turma Criminal. 2. Conflito julgado procedente, declarando-se competente a $2^{\mathrm{a}}$ Turma Criminal. Unânime. (20080020137058CCP, Relator ESTEVAM MAIA, Conselho Especial, julgado em 11/11/2008, DJ 28/01/2009 p. 47)

PENAL E PROCESSUAL PENAL. AMEAÇA. VIOLÊNCIA DOMÉSTICA. PRELIMINAR: APELO INTERPOSTO COM APOIO NAS REGRAS DO PROCESSO CIVIL. ADMISSIBILIDADE, EM FACE DE ERRO JUSTIFICÁVEL CAUSADO PELO PRÓPRIO SENTENCIANTE. MÉRITO: CONCESSÃO DE MEDIDA PROTETIVA DE AFASTAMENTO DO LAR CONJUGAL. AUSÊNCIA DE FUNDAMENTAÇÃO. PRINCÍPIOS DO CONTRADITÓRIO E DA AMPLA DEFESA. NÃO OBSERVÂNCIA. NULIDADE. 1.Apesar da natureza penal da decisão resistida, o recurso de apelo, interposto de acordo com as regras processuais civis, não pode ser considerado intempestivo se o próprio julgador que proferiu a sentença resolveu o feito com base no art. 269, inciso I, do Código de Processo Civil, levando o apelante, portanto, a erro justificável (...) 3. Apelo conhecido e provido. (20060111217028APR, Relator ARNOLDO CAMANHO DE ASSIS, $2^{\text {a }}$ Turma Criminal, julgado em 02/04/2009, DJ 24/06/2009 p. 247)

AGRAVO DE INSTRUMENTO - NÃO CONHECIMENTO - HABEAS CORPUS - CONCESSÃO DE OFÍCIO - POSSIBILIDADE - LEI MARIA DA PENHA MEDIDAS PROTETIVAS - MODULAÇÃO DE INTENSIDADE - ORDEM PARCIALMENTE MODIFICADA 1) - Não se conhece, em Turma Criminal, de agravo de instrumento, que é recurso cível, previsto no artigo 522 do CPC, sendo competente para dele conhecer Turma Criminal (sic), nos precisos termos do artigo 18, I, do Regimento Interno desta Casa. 2) - Possível conceder-se, de ofício, Habeas Corpus, nos exatos termos do $\S 2^{\circ}$, do artigo 644, do CPP (...). 3) - Agravo de instrumento não conhecido. Habeas Corpus concedido de ofício, parcialmente. (20100020000138AGI, Relator LUCIANO MOREIRA VASCONCELLOS, $1^{\text {a }}$ Turma Criminal, julgado em 18/02/2010, DJ 19/03/2010)

FUNDAMENTADO NO ART. 888, VI, DO CÓDIGO DE PROCESSO CIVIL, BEM COMO NA CONVENIÊNCIA E COMODIDADE DA AGRAVANTE E DOS SEUS DESCENDENTES. PROVIDÊNCIA DE NATUREZA CÍVEL. IMPOSSIBILIDADE DE AS CÂMARAS CRIMINAIS REGULAREM DIREITO PATRIMONIAL. REMESSA A UMA DAS CÂMARAS DE DIREITO CIVIL. RECURSO NÃO CONHECIDO. REDISTRIBUIÇÃO. - As tutelas de urgência definidas pela Lei Maria da Penha possuem natureza cível e criminal, cuja competência, no primeiro grau de jurisdição, é regulada pelo art. 33 da legislação. No âmbito recursal, a lei é omissa quanto à competência, o que torna essencial 
distinguir a natureza jurídica da medida para fins de distribuição do processo. - A medida protetiva de urgência consistente no afastamento do agressor do lar (Lei 11.340/2006, art. 22, II), que visa a manutenção da suposta vítima e dos seus descendentes no lar conjugal, a fim de melhor atender à conveniência e comodidade destes, possui natureza jurídica cível, razão porque não poderá ser apreciada pelas Câmaras Criminais deste Tribunal de Justiça. - Recurso não conhecido e redistribuído a uma das Câmaras de Direito Civil desta Corte.72 BRASIL, Tribunal de Justiça de Santa Catarina. Agravo de Instrumento. AGRAVO POR INSTRUMENTO. MARIA DA PENHA. MEDIDA PROTETIVA DE URGÊNCIA. AFASTAMENTO DO LAR (LEI 11.340/2006, ART. 22, II). COMPETÊNCIA. RECURSO QUE OBJETIVA A MANUTENÇÃO DA SUPOSTA VÍTIMA E DOS FILHOS DO CASAL NA RESIDÊNCIA CONJUGAL. AGRAVO FUNDAMENTADO NO ART. 888, VI, DO CÓDIGO DE PROCESSO CIVIL, BEM COMO NA CONVENIÊNCIA E COMODIDADE DA AGRAVANTE E DOS SEUS DESCENDENTES. PROVIDÊNCIA DE NATUREZA CÍVEL. IMPOSSIBILIDADE DE AS CÂMARAS CRIMINAIS REGULAREM DIREITO PATRIMONIAL. REMESSA A UMA DAS CÂMARAS DE DIREITO CIVIL. RECURSO NÃO CONHECIDO. REDISTRIBUIÇÃO. AG: 20130753596 SC 2013.075359-6. Primeira Câmara Criminal. M. dos S. e J. K. Santa Catarina, 11 nov. 2013. Disponível em: <http://tj-sc.jusbrasil.com.br/jurisprudencia/24649906/agravode-instrumento-ag-20130753596-sc-2013075359-6-acordao-tjsc> Acesso em: 05 abr. 2015 .

Nesse último acórdão, é interessante notar que a solução do TJSC foi de que o recurso cabível contra decisão das MPUs vai depender da medida protetiva sobre a qual a decisão do juízo a quo foi tomada: se de natureza penal, para as câmaras criminais; se de natureza cível, para as câmaras cíveis.

O que se pode concluir é a premente necessidade de que, sempre que uma MPU for ajuizada, torna-se indispensável tomar conhecimento sobre a tramitação de outras ações, sejam de natureza penal e/ou de família, para que as decisões não entrem em conflito. Imagine-se a hipótese: em relação ao mesmo agressor e vítima há uma ação penal que foi julgada procedente, uma ação de guarda e alimentos, e a MPU será extinta porque tramita em outro juízo, subsistindo o conflito. É de grave situação jurídica essa hipótese. Assim, os sistemas eletrônicos de peticionamento devem acusar esse tipo de informação para que o juiz, ciente de todo o conjunto complexo que a violência doméstica implica e seus efeitos em outras áreas do Direito (criminal, de família, cível, sucessões, etc.), possa decidir de forma adequada e evitar decisões conflitantes, sem colocar em risco a segurança e vida da vítima e, até mesmo, de seus filhos.

Outra proposta salutar para esse problema é colocada por Alexandre Freitas Câmara (2009, p. 261), que propõe a criação, em segunda instância, de uma Câmara Especializada com competência para causas cíveis e criminais decorrentes da prática de violência doméstica, tal como se dá com as turmas recursais. E acrescente-se: composta por magistrados oriundos 
de varas cíveis e criminais. Ressalte-se que os membros dessa câmara, a exemplo de todo e qualquer outro operador de Direito que faça parte das instituições do sistema de justiça, devem necessariamente ser submetidos a processo de formação continuada, a qual priorize conhecimentos científicos transdisciplinares, sobretudo aqueles relacionados à complexidade e peculiaridades da violência de gênero e da violência doméstica. Desse modo, é possível se afastar da hipossuficiência técnica que tanto dificulta a aplicação da LMP, revitimiza as mulheres e acrescenta ao ciclo de violência já vivido pelas vítimas a violência institucional, em especial quando perpetrada pelo Estado por falta de conhecimento especializado.

\section{CONCLUSÕES}

A LMP trouxe consigo uma mudança paradigmática no enfrentamento da violência doméstica e familiar contra a mulher, tanto em relação ao agressor quanto à vítima. Aos olhos do texto da lei, a vítima passou a ser respeitada em sua condição de sujeito de direitos em situação peculiar de violência.

Nesse contexto, as MPUs são um importante instrumento para fazer cessar a situação de violência que vem historicamente subjugando a mulher. Assim, são previstas medidas pela LMP, como a prestação de alimentos provisionais, encaminhamento da ofendida e seus dependentes a programa oficial ou comunitário de proteção, ou de atendimento em favor da mulher, ou determinação para que o agressor se afaste do lar, domicílio ou local de convivência com a ofendida (arts. 22 a 24).

Todavia, é objeto de celeuma a natureza jurídica das MPUs, se de natureza civil e/ou penal, o que traz importantes consequências para a definição de competência ao julgar tais medidas e possíveis recursos em decorrência de seus deferimentos e/ou indeferimentos.

Em que pese respeitável posição da doutrina majoritária, entende-se, pelos diversos argumentos expostos ao longo do trabalho, que o mais acertado consiste em considerar as MPUs como de natureza cível, já que, ao considerá-las como de natureza penal, leva-se à sua extinção sem que o processo criminal tenha sequer iniciado, como comumente ocorre.

Diante disso, a insegurança jurídica desse quadro leva a concluir que se faz premente a adoção de duas medidas: a alteração dos sistemas eletrônicos de peticionamento, para que informem sempre sobre a existência de ação penal, de família, cível ou de outra MPU, propiciando ao magistrado conhecimento do caso em seus mais diversos reflexos; e a 
existência de uma Câmara Especializada, com competência para causas cíveis e criminais decorrentes da prática de violência doméstica, tal como proposto pelo processualista Alexandre Freitas Câmara (2009).

A insegurança jurídica que nasce dessa controvérsia aliada à hipossuficiência técnica transdisciplinar, que permite a real compreensão da complexidade do fenômeno e que se pretende combater, materializada em diversas decisões e sentenças proferidas nas varas especializadas e/ou varas únicas, evocando-se a Lei Maria da Penha, é sintoma bastante grave da violência institucional perpetrada pelo próprio Poder Judiciário. Tal violência, mais uma vez, acaba por revitimizar a mulher e lhe nega a possibilidade concreta de exercer seu direito a uma vida livre de violência.

\section{REFERÊNCIAS}

ÁVILA, Thiago André Pierobom de et al. Modelos Europeus de Enfrentamento à Violência de Gênero. Experiências e Representações Sociais. Brasília, DF: ESMPU, 2014. Disponível em: <http://escola.mpu.mp.br/linha-editorial/outras-publicacoes/MEEVG-Ebook.pdf>. Acesso em: 14 dez. 2016.

BRASIL. Constituição da República Federativa do Brasil, 1988. Disponível em: <http://www.planalto.gov.br/ccivil_03/constituicao/ConstituicaoCompilado.htm>. Acesso em: 19 nov. 2016.

. Lei n. 13.105, de 16 de março de 2015. Código de Processo Civil. Disponível em: <http://www.planalto.gov.br/ccivil_03/_ato2015-2018/2015/lei/113105.htm>. Acesso em: 14 dez. 2016.

Decreto-lei $\mathrm{n}^{\circ}$ 3.689, de 3 de outubro de 1941. Código de Processo Penal. Disponível em: <http://www.planalto.gov.br/ccivil_03/decreto-lei/Del3689.htm>. Acesso em: 14 dez. 2016.

Lei 11.340, de 07 agosto de 2006. Cria mecanismos para coibir a violência doméstica e familiar contra a mulher, nos termos do $\S 80$ do art. 226 da Constituição Federal, da Convenção sobre a Eliminação de Todas as Formas de Discriminação contra as Mulheres e da Convenção Interamericana para Prevenir, Punir e Erradicar a Violência contra a Mulher; dispõe sobre a criação dos Juizados de Violência Doméstica e Familiar contra a Mulher; altera o Código de Processo Penal, o Código Penal e a Lei de Execução Penal; e dá outras providências. Disponível em: <http://www.planalto.gov.br/ccivil_03/_ato20042006/2006/lei/111340.htm>. Acesso em: 14 dez. 2016.

Superior Tribunal de Justiça. Habeas Corpus no 220.392/RJ. Julg.: 25 fev. 2014. Disponível em < http://stj.jusbrasil.com.br/jurisprudencia/24978876/habeas-corpus-hc- 
220392-rj-2011-0235315-0-stj/inteiro-teor-24978877>. Acesso em: 14 dez. 2016.

. Supremo Tribunal Federal. Habeas Corpus n⿳0 88452/RS. Segunda Turma. Ministro

Relator Eros Grau. Distrito Federal, 02 maio 2006. Disponível em <http://stf.jusbrasil.com.br/jurisprudencia/760839/habeas-corpus-hc-88452-rs>. Acesso em: 14 dez. 2016.

Conselho Nacional de Justiça. O Poder Judiciário na aplicação da Lei Maria da Penha. Disponível em: <http://www.cnj.jus.br/images/programas/lei-maria-dapenha/cartilha_maria_da_penha.pdf >. Acesso em: 20 dez. 2015.

BECHARA, Júlia Maria Seixas. Violência doméstica e natureza jurídica das medidas protetivas de urgência. Disponível em: <http://www.ibdfam.org.br/novosite/artigos/detalhe/689>. Acesso em: 14 dez. 2016.

CÂMARA, Alexandre Freitas. A lei da violência doméstica e familiar contra a mulher e o processo civil. Revista de Processo, São Paulo, v. 34, n. 168, p. 255-265, fev. 2009. p. 258.

CAMPOS, Carmen H.; CARVALHO, Salo. Tensões atuais entre a criminologia feminista e a criminologia crítica: a experiência brasileira. In: CAMPOS, Carmen H. (Org.). Lei Maria da Penha (comentada em uma perspectiva jurídico-feminista). Rio de Janeiro: Lumen Juris, 2011.

CARVALHO, Marcia Haydée Porto de. Brasil. Lei 11.340/2006. In: CEBALLOS, Elena, B. Marín de Espinosa (Org.). Régimen jurídico de la violencia de género en Iberoamérica e Espanha - Um estúdio de las leyes integrales de segunda generación. 1. ed. v. 1. Madrid: Aranzadi, 2015, p. 47-77.

CASTILHO, Ela Wiecko V. A Lei Maria da Penha e o Ministério Público. Compromisso e atitude, 21 nov. 2016. Disponível em: <http://www.compromissoeatitude.org.br/a-lei-mariada-penha-e-o-ministerio-publico-por-ela-wiecko-v-decastilho/>. Acesso em: 14 dez. 2016.

CAVALCANTI, Stela V. S. de Farias. Violência doméstica contra a mulher no Brasil: análise da Lei Maria da Penha. Salvador: Juspodivm, 2007.

CELMER, Elisa Girotti; AZEVEDO, Rodrigo Ghiringhelli de. Violência de gênero, produção legislativa e discurso punitivo: uma análise da Lei $\mathrm{n}^{\circ}$ 11.340/2006. Boletim IBCCRIM, São Paulo, ano 14, n. 170, p. 15-17, jan. 2007.

DIAS, Maria Berenice. A Lei Maria da Penha na Justiça: A efetividade da Lei $\mathrm{n}^{\mathbf{o}}$ 11.340/2006 de combate à violência doméstica e familiar contra a mulher. 3. ed. rev., atual. e ampl. São Paulo: Revista dos Tribunais, 2012.

DIDIER JR, Fredie; OLIVEIRA, Rafael. Aspectos processuais civis da Lei Maria da Penha: violência doméstica e familiar contra a mulher. Evocati, n. 58, 29 out. 2010. Disponível em: $<\mathrm{http}: / /$ www.evocati.com.br/evocati/artigos.wsp?tmp_codartigo=449>. Acesso em: 13 nov. 2016. 
DISTRITO FEDERAL. Tribunal de Justiça do Distrito Federal e Territórios. Habeas Corpus $n^{0}$ : 20130020302976 DF 0031251-16.2013.8.07.0000. Primeira Turma Criminal. Distrito Federal, $\quad 09 \quad$ jan. $2014 . \quad$ Disponível em: <http://tjdf.jusbrasil.com.br/jurisprudencia/116286646/habeas-corpus-hbc-20130020302976-df0031251-1620138070000>. Acesso em: 14 dez. 2016.

. Tribunal de Justiça do Distrito Federal e Territórios. Recurso em Sentido Estrito $\mathbf{n}^{\mathbf{o}}$ 20130710330523 DF 0032108-41.2013.8.07.0007. 2 $2^{\text {a }}$ Turma Criminal. Relator: SOUZA E AVILA, Distrito Federal, 29 maio 2014. Disponível em: <http://tj62df.jusbrasil.com.br/jurisprudencia/122795992/recurso-em-sentido-estrito-rse20130710330523-df-0032108-4120138070007>. Acesso em: 14 dez. 2016.

FOLEY, Gláucia Falsarella. Lei Maria da Penha: lei de emancipação da mulher? In: Revista dos Tribunais, São Paulo, v. 894, n. 99, p. 443-459, abr. 2010.

FONAVID. Enunciados. Rio de Janeiro, 2009. Disponível em: <http://www.amb.com.br/fonavid/ENUNCIADOS.pdf>. Acesso em: 14 dez. 2016.

LAVORENTI, Wilson. Violência e discriminação contra a mulher: tratados internacionais de proteção e o direito penal brasileiro. Campinas: Millenium Editora, 2009.

MASTROBUONO, Carla Mirella. Em busca dos braços da vênus: lacunas do saber e questão feminina. Revista Brasileira de Ciências Criminais, São Paulo, vol. 25, p. 246, jan. 1999.

MENEGHEL, Stela Nazareth et al. Rotas críticas de mulheres em situação de violência: depoimentos de mulheres e operadores em Porto Alegre, Rio Grande do Sul, Brasil. Cad. Saúde Pública, Rio de Janeiro, v. 27, n. 4, p. 743-752, Abr. 2011. Disponível em: $<$ http://www.scielo.br/scielo.php?script=sci_arttext\&pid=S0102-

311X2011000400013\&lng=en\&nrm=iso>. Acesso em: 14 dez. 2016.

MINAS GERAIS. Tribunal de Justiça de Minas Gerais. Apelação Criminal. APELAÇÃo CRIMINAL 10287130041737001/MG. $7^{a}$ Câmara Criminal. Desemb. Rel. Ricardo Donizete da Silva. Julg.: 17 dez. 2013. Disponível em: <http://tjmg.jusbrasil.com.br/jurisprudencia/118694802/apelacao-criminal-apr-10287130041737001mg>. Acesso em: 14 dez. 2016.

Tribunal de Justiça de Minas Gerais. Apelação Criminal no 10287130041737001/MG. $7^{\text {a }}$ Câmara Criminal. Julg.: 17 dez. 2013. Disponível em: <http://tjmg.jusbrasil.com.br/jurisprudencia/118694802/apelacao-criminal-apr-10287130041737001mg> Acesso em: 14 dez. 2016.

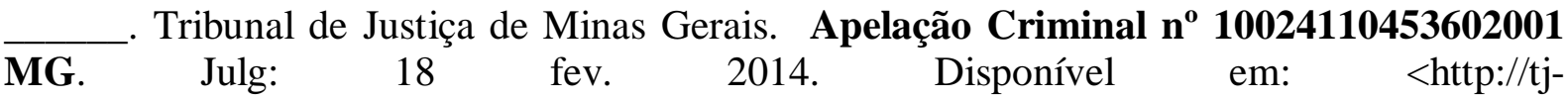
mg.jusbrasil.com.br/jurisprudencia/119363582/apelacao-criminal-apr-10024110453602001mg>. Acesso em: 14 dez. 2016.

Tribunal de Justiça de Minas Gerais. Apelação Criminal no.1.0024.07.8064524/001. $4^{\text {a }}$ Câmara Criminal. Relator Des. Herbert Carneiro. Minas Gerais, 10 jun. 2014. 
Disponível em: <http://tj-mg.jusbrasil.com.br/jurisprudencia/124382715/apelacao-criminalapr-10024120245014001-mg/inteiro-teor-124382764>. Acesso em: 14 dez. 2016.

- Tribunal de Justiça de Minas Gerais. Recurso em Sentido Estrito no 1.0024.10.044200-3/001. 5a Câmara Criminal. Julg.: 18 mar. 2014. Disponível em: <http://tjmg.jusbrasil.com.br/jurisprudencia/119542242/rec-em-sentido-estrito-10024100442003001mg/inteiro-teor-119542352>. Acesso em: 14 dez. 2016.

MOSCHOVICH, Marília. Por que as mulheres estão sempre erradas? Carta Capital, 01 jul. 2014. Disponível em: <http://www.cartacapital.com.br/blogs/outras-palavras/para-umaestetica-das-mulheres-erradas-9396.html>. Acesso em: 14 dez. 2016.

NASH, Claudio; MUJICA, Ignacio; CASAS, Lidia. Protocolo de actuación para operadores de justicia frente a la violencia contra las mujeres en el marco de las relaciones de pareja. Chile: Universidad de Chile, Facultad de Derecho, Centro de Derechos Humanos, 2011. Disponível em: 〈http://www.cdh.uchile.cl/media/publicaciones/pdf/83.pdf>. Acesso em: 17 jan. 2017.

NUCCI, Guilherme de Souza. Leis penais e processuais penais comentadas. 5. ed. São Paulo: RT, 2010.

ORGANIZAÇÃO DOS ESTADOS AMERICANOS. Convenção Interamericana para Prevenir, Punir e Erradicar a Violência contra a Mulher, de 9 de junho de 1994. Disponível em: <https://www.cidh.oas.org/basicos/portugues/m.Belem.do.Para.htm>. Acesso em: 17 jan. 2017.

PASINATO, Wânia. Lei Maria da Penha Novas abordagens sobre velhas propostas. Onde avançamos? In: Civitas, Porto Alegre, v. 10, n. 2, p. 216-232, maio-ago. 2010.

PIMENTEL, Silvia; PANDJIARJIAN, Valéria. Percepções das mulheres em relação ao Direito e à justiça: legislação, acesso e funcionamento. Porto Alegre: Sergio Antonio Fabris Editor, 1996.

RAZERA, Josiane et al. Violência Doméstica e Transgeracionalidade: Um Estudo de Caso. Revista de Psicologia da IMED, v. 6, n. 1, p. 47-51, Jan-Jun, 2014.

RIO GRANDE DO SUL. Tribunal de Justiça do Rio Grande do Sul. Agravo de Instrumento $\mathbf{n}^{\circ} \mathbf{7 0 0 4 3 2 2 0 1 7 7}$ RS. Segunda Câmara Criminal. Laiziane Cristina Tigre da Silva e Ministério Público. Disponível em: <http://tj-63rs.jusbrasil.com.br/jurisprudencia/113524516/peticaopet-70043220177-rs/inteiro-teor-113524526>. Acesso em: 14 dez. 2016.

RUA, Maria das Graças. Políticas públicas. 2. ed. reimp. Florianópolis: Departamento de Ciências da Administração/UFSC, 2012. Disponível em: $<$ https://www.academia.edu/11259556/Politicas_Publicas__Maria_das_Gra\%C3\%A7as_Rua>. Acesso em: 14 dez. 2016.

SAFFIOTI, Heleieth I. B. Gênero, patriarcado e violência. São Paulo: Editora Fundação Perseu Abramo, 2005 (Coleção Brasil Urgente), p. 132-135. 
- Ontogênese e filogênese do gênero: ordem patriarcal de gênero e a violência masculina contra mulheres. Curso nacional de formação político-sindical da Enfoc, Brasília, 2008. Disponível em: <http://www.enfoc.org.br/web/arquivos/documento/14/f1269ontogenese-e-filogenese-dogenero---heleieth-saffioti---2006.pdf>. Acesso em: 14 dez. 2016.

SANTA CATARINA. Tribunal de Justiça de Santa Catarina. Agravo de Instrumento $\mathbf{n}^{\mathbf{o}}$ 20130753596 SC 2013.075359-6. Primeira Câmara Criminal. Julg.: 11 nov. 2013. Disponível em: $\quad<$ http://tj-sc.jusbrasil.com.br/jurisprudencia/24649906/agravo-de-instrumento-ag20130753596-sc-2013075359-6-acordao-tjsc>. Acesso em: 14 dez. 2016.

SOUZA, Sérgio Ricardo de. Comentários à lei de combate à violência contra a mulher. 3 . ed. Curitiba: Juruá, 2009. 